\title{
Analysis of Student Errors in Solving Mathematics Problems Based on Watson's Criteria on the Subject of Two Variable Linear Equation System (SPLDV)
}

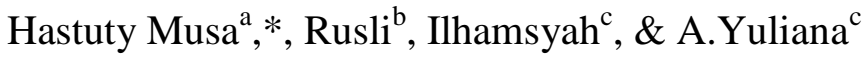 \\ ${ }^{a}$ Department of Mathematics, Universitas Muhammadiyah Parepare, Indonesia \\ ${ }^{b}$ Department of Mathematics, Universitas Negeri Makassar, Indonesia \\ ${ }^{c}$ Department of Mathematics, Universitas Muhammadiyah Makassar, Indonesia
}

\begin{abstract}
The purpose of the study was to describe the types of student errors and the factors that caused students to make mistakes in solving a two-variable system of linear equations based on Watson's criteria for class VIII MTs Pattuku. This type of research is descriptive research using a qualitative approach. The subjects in this study were students of class VIII MTs Pattuku then chose 3 subjects to be interviewed who had the most types of errors based on Watson's criteria. The research instrument used was a diagnostic test consisting of 3 questions about a two-variable linear equation system and interview guidelines. From the results of this study, it shows that there are no students who make mistakes in missing data (committed data) and indirect manipulation (undirected manipulation). 16\% made incorrect data errors (innapropriate data), 40\% made incorrect procedural errors (innapropriate procedure), 68\% made an omitted conclusion error, $24 \%$ made a response level conflict error, 36\% made mistakes in the skill hierarchy problem, and $48 \%$ made mistakes other than the 7 categories above (above other).
\end{abstract}

Keywords: Error analysis, two variable linear equation System, Watson criteria.

\section{Introduction}

Matematika adalah mata pelajaran yang diajarkan pada setiap jenjang pendidikan yang dimulai dari SD, SMP, SMA sampai keperguruan tinggi (Isrokatun, Hanifah, Maulana, \& Suhaebar, 2020). Matematika dapat menjadi kebutuhan untuk memberikan kehidupan manusia. Hal ini terlihat dari aktivitas manusia yang tidak dapat dipisahkan dari matematika, seperti dalam membilang benda, jual beli, kegiatan mengukur suatu besaran dan lain sebagainya.

Dalam menyelesaikan masalah, seseorang diharapkan mampu mengantisipasi dan memikirkan apa yang akan dilakukan, sehingga memerlukan kemampuan menganalisis kesalahan siswa agar pembelajaran dapat berjalan dengan baik dengan demikian akan memberikan hasil pembelajaran yang optimal, selain itu juga dapat dijadikan sebagai bahan evaluasi bahwa letak kesalahan yang dilakukan oleh siswa (Yudianto, 2016). Kesalahan merupakan suatu bentuk penyimpangan pada sesuatu yang telah dianggap benar, sistematis, konsisten, atau bentuk penyimpangan terhadap sesuatu yang telah disepakati sebelumnya (Wijaya \& Masriyah. 2011).

Pada banyak literatur, diperoleh bahwa terdapat 8 jenis kriteria kesalahan siswa yang meliputi data tidak tepat (inappropriate data/id), prosedur tidak tepat (inappropriate procedure/ip), data hilang (omitted data/od), kesimpulan hilang (ommited conclusion/oc), konflik level respon (response level conflic/rlc), manipulasi tidak langsung (undirected manipulation/um), masalah hirarki keterampilan (skills hierarchy problem/shp), dan selain ketujuh kriteria di atas (above other/ao) (Santrock, 2012). Kriteria Watson ini digunakan dalam menganalisis kesalahan siswa dengan harapan agar kesalahan siswa dalam menyelesaikan soal matematika dengan materi tertentu terungkap sehingga

\footnotetext{
* Corresponding author.

E-mail address: hastuty.rusli@gmail.com (Hastuty Musa)
} 
pendidik dapat menentukan cara yang tepat dalam pembelajaran untuk meningkatkan hasil belajar siswa di sekolah. Pendidik tidak hanya dituntut untuk mengetahui kesalahan yang terjadi pada siswa saat mengerjakan soal matematika. Pendidik juga harus mengetahui faktor lain yang bisa mempengaruhi kesalahan siswa saat mengerjakan soal matematika, yaitu kemampuan matematika dan gender. Oleh sebab itu, perlu adanya analisis kesalahan siswa secara mendetail agar pendidik bisa mengeksplorasi kesalahan siswa dan mengetahui jenis kesalahan yang terjadi pada siswa (Saputri, Sugiarti, Murtikusuma, Trapsilasiwi, \& Yudianto, 2018).

Kemampuan siswa dalam menyelesaikan soal matematika merupakan keterampilan yang dimiliki seseorang untuk dapat menyelesaikan suatu soal matematika. Kemampuan siswa dalam menyelesaikan soal matematika dapat dilihat dari perolehan hasil belajar. Kemampuan matematika dibagi menjadi 3 tingkatan, yaitu kemampuan matematika tingkat tinggi, sedang, dan rendah (Arikunto, 1993).

Kesalahan yang sering juga terjadi dalam menyelesaikan soal matematika diantaranya adalah kekeliruan dalam menghitung, kesalahan dalam menguasai ciri serta simbol, kesalahan dalam menguasai rumus serta konsep matematika, dan kesalahan dalam memilah serta memakai langkah penyelesaian. Kamariah (2018), mengatakan bahwa meskipun telah banyak siswa yang nilainya telah mencapai nilai KKM ( Kriteria Ketuntasan Minimun) namun masih ada sebagian dari siswa yang nilainya belum menggapai KKM( Kriteria Ketuntasan Minimun). Perihal tersebut diakibatkan karena siswa belum bisa menyelesaikan permasalahan matematika sehingga siswa masih membuat kesalahan dalam mengerjakan ataupun menyelesaikan soal matematika.

Berdasarkan wawancara oleh guru Matematika MTs Pattuku, pada tanggal 10 Agustus 2020 mengatakan bahwa kebanyakan siswa di MTs Pattuku mengalami kesalahan pada saat menyelesaikan soal dengan materi SPLDV. Ketika diberikan soal terkait materi sistem persamaan linear dua variabel peserta didik masih salah dalam mengerjakan soal tersebut. Dalam penelitian ini, digunakan kriteria Watson untuk melihat kesalahan siswa dalam menyelesaikan materi sistem persamaan linear dua variabel dan faktor penyebab siswa melakukan kesalahan. Adapun delapan jenis kriteria kesalahan Watson yaitu innapropriate data, innappropriate procedure, ommited data, ommited conclusion, response level conflict, undirected manipulation, skill hierarchy problem, dan above other. Akan dijadikan acuan dalam menganalisis kesalahan yang dilakuka oleh siswa dalam menyelesaikan soal-soal SPLDV.

\section{Methods}

Penelitian ini merupakan penelitian deskriptif melalui pendekatan kualitatif. dengan tujuan untuk mengetahui jenis kesalahan apa yang dilakukan siswa dan faktor-faktor yang menyebabkan siswa melakukan kesalahan. Instrumen utama dalam penelitian kualitatif adalah peneliti itu sendiri. Selain instrumen utama, terdapat juga instrumen bantu yang berupa soal tes dan pedoman wawancara. Penelitian ini dilakukan di MTs Pattuku yang beralamat di desa Pattuku Kecamatan Bontocani Kabupaten Bone.

Penelitian ini dilakukan terhadap siswa kelas VIII Mts Pattuku. Subjek penelitian dalam penelitian ini adalah siswa kelas VIII MTs Pattuku. Jumlah siswa adalah 25 siswa sedangkan untuk diwawancarai, peneliti memilih 3 orang siswa yang memiliki jenis kesalahan terbanyakberdasarkan kriteria Watson dengan cara memberikan tes diagnostik kemudian mendata jenis kesalahan yang dilakukan siswa. Peneliti melakukan wawancara untuk mengetahui faktor penyebab terjadinya siswa melakukan kesalahan dalam menyelesaikan soal sistem persamaan linear dua variabel.

Teknik pengumpulan data dalam penelitian ini yaitu soal tes dan wawancara. Dalam penelitian ini digunakan teknik analisis data deskriptif kualitatif dengan tahap-tahap sebagai berikut: tahap reduksi data, tahap penyajian data, dan tahap menarik kesimpulan.

\section{Results and Discussion}

Dalam menganalisis kesalahan siswa diperlukan indikator faktor penyebab kesalahan menurut Watson yang dapat dilihat pada Tabel 1. 
Tabel 1. Indikator Faktor Penyebab Kesalahan Berdasarkan Kriteria Watson

\begin{tabular}{|c|c|c|}
\hline Kriteria Watson & Indikator & Penyebab \\
\hline $\begin{array}{l}\text { Data tidak tepat } \\
\text { (innappropriate data) }\end{array}$ & $\begin{array}{l}\text { a. Rumus yang digunakan } \\
\text { tidak benar (salah rumus) } \\
\text { b. Salah memasukkan data ke } \\
\text { variabel } \\
\text { c. Salah memasukkan data yang } \\
\text { diketahui pada soal ke dalam } \\
\text { keterangan yang diketahui }\end{array}$ & $\begin{array}{l}\text { a. Siswa salah dalam menggunakan } \\
\text { rumus } \\
\text { b. Siswa kurang teliti dalam } \\
\text { pengerjaan } \\
\text { c. Siswa belum mengerti data yang } \\
\text { sudah diketahui pada soal }\end{array}$ \\
\hline $\begin{array}{l}\text { Prosedur tidak tepat } \\
\text { (inappropriate } \\
\text { procedure) }\end{array}$ & $\begin{array}{l}\text { a. Tidak menggunakan cara } \\
\text { yang tepat dalam } \\
\text { pengerjaan } \\
\text { b. Menuliskan langkah- } \\
\text { langkah yang tidak sesuai } \\
\text { dengan permasalahan } \\
\text { c. Tidak menggunakan } \\
\text { langkah-langkah yang akan } \\
\text { digunakan dalam } \\
\text { pengerjaan }\end{array}$ & $\begin{array}{l}\text { a. Tidak mengetahui cara yangharus } \\
\text { digunakan dalam pengerjaan } \\
\text { b. Tidak mengerti cara dalam } \\
\text { menuliskan langkah-langkah } \\
\text { penyelesaian } \\
\text { c. Belum mengerti maksudmaksud } \\
\text { dari soal }\end{array}$ \\
\hline $\begin{array}{l}\text { Data hilang (ommited } \\
\text { data) }\end{array}$ & $\begin{array}{l}\text { Kehilangan satu data atau } \\
\text { lebih }\end{array}$ & Kurang teliti dalam menyajikandata \\
\hline $\begin{array}{l}\text { Kesimpulan hilang } \\
\text { (omitted conclusion) }\end{array}$ & $\begin{array}{l}\text { Tidak menggunakan data yang } \\
\text { sudah diperoleh untuk } \\
\text { membuat kesimpulan dari } \\
\text { jawaban permasalahan }\end{array}$ & $\begin{array}{l}\text { Tidak mampu mengkaitkan data-data } \\
\text { yang sudah diperoleh untuk mencapai } \\
\text { kesimpulan }\end{array}$ \\
\hline $\begin{array}{l}\text { Konflik level respon } \\
\text { (response level conflict) }\end{array}$ & $\begin{array}{l}\text { Kurang kesiapan yang } \\
\text { maksimal dalam pengerjaan }\end{array}$ & $\begin{array}{l}\text { Kurang merespon dengan baikmaksud } \\
\text { dari soal }\end{array}$ \\
\hline $\begin{array}{l}\text { Manipulasi tidak } \\
\text { langsung (undirected } \\
\text { manipulation) }\end{array}$ & $\begin{array}{l}\text { Menggunakan alasan yang } \\
\text { acak atau tidak logis dalam } \\
\text { pengerjaan }\end{array}$ & $\begin{array}{l}\text { Bingung menggunakan alasan yang } \\
\text { tepat untuk menyelesaikansoal }\end{array}$ \\
\hline $\begin{array}{l}\text { Masalah hirarki } \\
\text { keterampilan (skill } \\
\text { hierarchy problem/shp) }\end{array}$ & $\begin{array}{l}\text { a. Tidak bisa menuangkan ide } \\
\text { aljabar } \\
\text { b. Melakukan kesalahandalam } \\
\text { menghitung }\end{array}$ & $\begin{array}{l}\text { a. Adanya keraguan untuk } \\
\text { menuliskan ide yang ada dalam } \\
\text { pikiran } \\
\text { b. Kurang teliti dalam perhitungan }\end{array}$ \\
\hline $\begin{array}{l}\text { Selain ke-7 kategori di } \\
\text { atas (above other) }\end{array}$ & $\begin{array}{l}\text { a. Menulis ulang soal } \\
\text { b. Tidak menuliskan jawaban } \\
\text { c. Menuliskan penyelesaian yang } \\
\text { tidak sesuai dengan perintah } \\
\text { soal }\end{array}$ & $\begin{array}{l}\text { a. Tidak mengetahui langkah- } \\
\text { langkah yang seharusnya ditulis } \\
\text { untuk menjawab } \\
\text { b. Tidak mengetahui maksud dari soal } \\
\text { sehingga tidak mempunyaijawaban } \\
\text { c. Kurang teliti dalam membaca } \\
\text { perintah soal }\end{array}$ \\
\hline
\end{tabular}

Hasil penelitian didapatkan dari subjek dalam hal ini adalah siswa kelas VIII MTs Pattuku. Pelaksanaan tes diikuti oleh 25 siswa. sedangkan pelaksanaan wawancara dipilih 3 siswa yang memiliki kesalahan terbanyak berdasarkan kriteria Watson. 
Tabel 2. Banyak kesalahan yang dilakukan siswa

\begin{tabular}{ccccccccc}
\hline \multirow{2}{*}{ No Soal } & \multicolumn{9}{c}{ Jenis Kesalahan } & um & shp & ao \\
\cline { 2 - 10 } & id & ip & od & oc & rlc & um & 4 \\
\hline 1 & 2 & 5 & 0 & 7 & 1 & 0 & 3 & 3 \\
\hline 2 & 1 & 2 & 0 & 7 & 2 & 0 & 3 \\
\hline Jumlah & 1 & 3 & 0 & 3 & 3 & 0 & 9 & 12 \\
\hline
\end{tabular}

Ket:

$$
\begin{array}{ll}
\text { id } & \text { : innappropriate data } \\
\text { ip } & \text { inappropriate procedure } \\
\text { od } & : \text { ommiteddata } \\
\text { oc } & : \text { omitted conclusion } \\
\text { rlc } & \text { response level conflict } \\
\text { um } & \text { : undirectedmanipulation } \\
\text { shp } & \text { skill hierarchy problem } \\
\text { ao } & \text { above other }
\end{array}
$$

Pada tabel 2, dapat dilihat bahwa siswa yang melakukan kesalahan terbanyak adalah pada kritria kesimpulan hilang. 4 siswa melakukan kesalahan data tidak tepat, 10 siswa melakukan kesalahan prosedur tidak tepat, 0 siswa melakukan kesalahan data hilang, 17 siswa melakukan kesalahan kesimpulan hilang, 6 siswa melakukan kesalahan konflik level respon, 0 siswa melakukan kesalahan manipulasi tilak langsung, 9 siswa melakukan kesalahan masalah hierarki keterampilan dan 12 siswa melakukan kesalahan selain ke-7 kategori diatas.

Secara umumnya, siswa dalam menyelesaikan soal-soal SPLDV yang diberikan telah menyelesaikan soal-soal tersebut, namun belum sampai pada kesimpulan tentang hasil yang diperoleh. Siswa belum memahami tentang hakekat dari SPLDV sehingga tidak mampu untuk melakukan evaluasi tentang jawaban yang mereka peroleh, siswa belum terampil untuk melakukan pengecekan bahwa jawaban yang ditemukan merupakan jawaban yang benar.

Sebagai contoh jawaban siswa sebagai berikut:

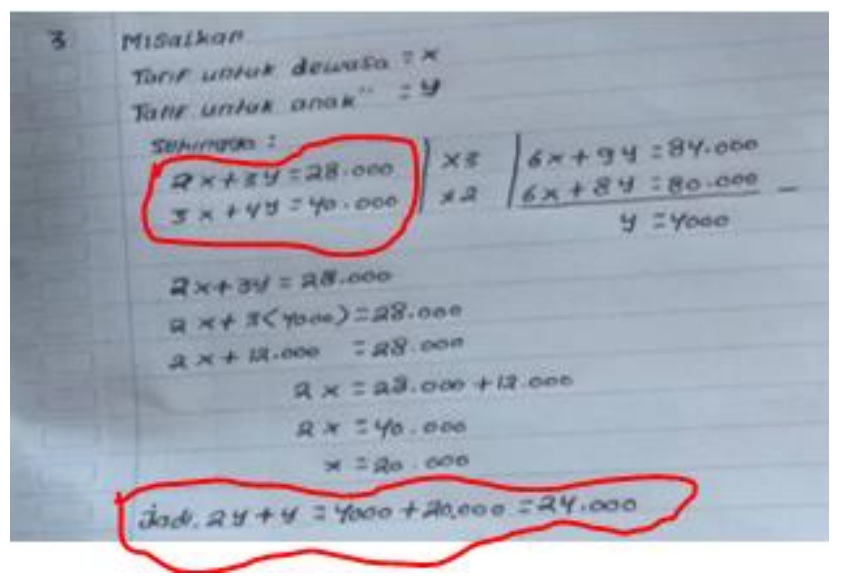

Secara khusus, temuan kesalahan-kesalahan yang terjadi diuraikan secara singkat berikut. 
Siswa dalam menyelesaikan soal-soal yang diberikan, kurang teliti dalam menyelesaikan soal sehingga mengakibatkan kesalahan, kesalahan ini dikategorikan kesalahan data tidak tepat, berikut cuplikan kesalahan yang dilakukan oleh siswa

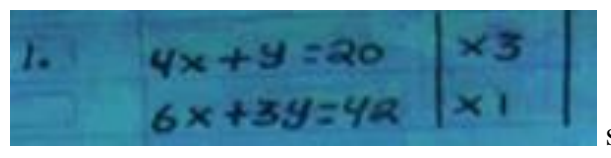

selanjutnya siswa mengerjakan

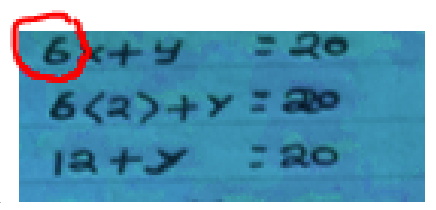

Siswa masih belum bisa melakukan kesalahan dalam menggunakan tanda bilangan. Kesalahan pada bagian ini misalnya terjadi pada contoh berikut: $-24 \div-3=-8$ yang seharusnya adalah 8 , kesalahan ini terulang pada beberapa kasus pertanyaan yang serupa yaitu -12000:-8 yaitu -1500 yang seharusnya adalah 1500 .
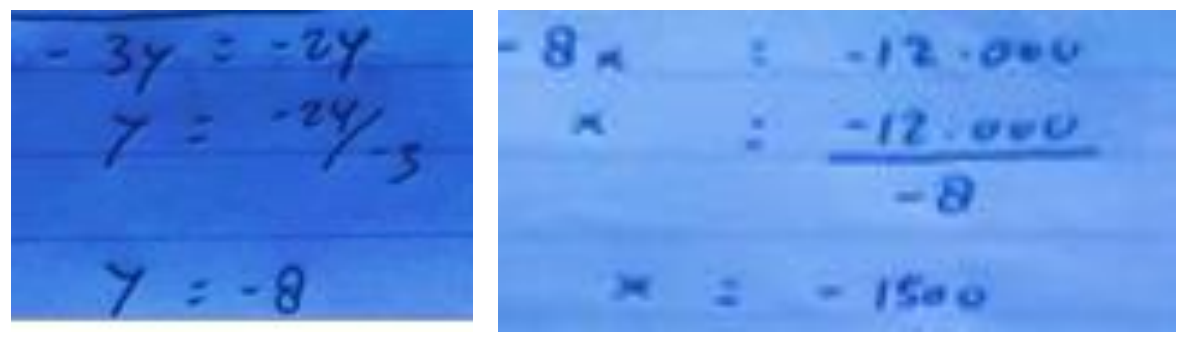

Kesalahan pada penggunaan tanda bilangan ini berdampak pada kesalahan dalam menetukan nilai suatu variabel, contoh untuk kasus ini adalah $x=\frac{-12000}{-8}=-1500$. Kesalahan yang terjadi akhirnya menjadi kesalahan yang beruntun, hal ini dapat kita lihat dari pekerjaan siswa, walaupun prosedurnya sudah benar namun karena nilai yang disubtitusikan itu sudah salah sehingga jawaban akhir siswa keliru, kasus ini dapat diberikan contoh sebagai berikut bahwa bila $x=-1500$ dan $2 x+3 y=6000$, sehingga $2(-1500)+3 y=6000$, diperoleh $3 y=6000+3000$.

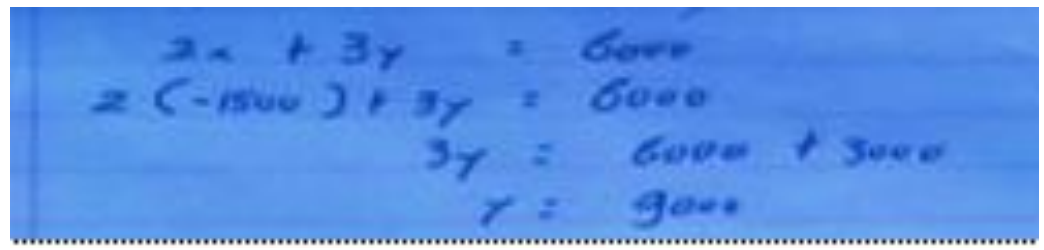

Kesalahan yang juga dipotret dari penelitian ini adalah siswa belum menguasai dengan baik tentang operasi bilangan, kesalahan ini terpotret melalui hasil pekerjaan siswa yang mengerjakan operasi $3 y=6000+3000$, sehingga y $=9000$, seharusnya $\mathrm{y}=(9000 / 3)=3000$.

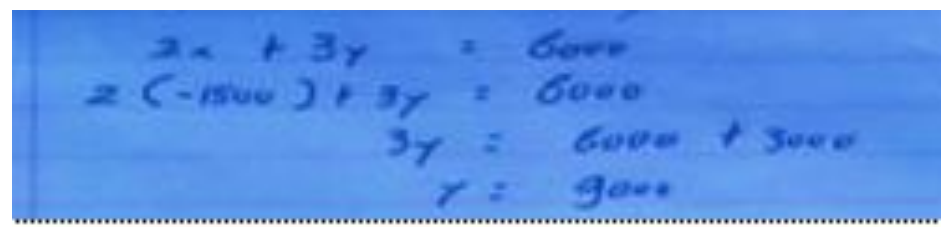

Siswa dalam menyelesaikan soal juga belum tuntas sampai akhir, sehingga tidak sampai pada kesimpulan, dengan demikian menurut kriteria Watson siswa juga masih mengalami kesulitan dalam kategori Kesimpulan hilang (omitted conclusion). 


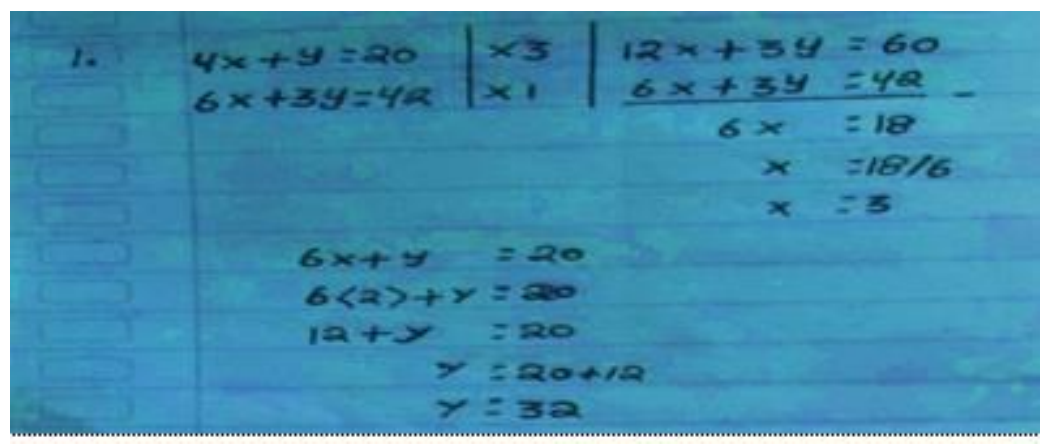

Penggunaan teknik menyelesaikan soal sistem persamaan linear belum dikuasai semuanya, hal ini terpotret bahwa siswa diminta untuk menyelesaikan soal dengan metode subtitusi, namun siswa menyelesaikan dengan metode eliminasi, rupa-rupanya siswa lebih menyenangi cara eliminasi untuk menyelesaikan soal SPLDV dibandingkan dengan metode lainnya.

\section{Conclusion}

Setelah penelitian dilakukan, dapat disimpulkan yaitu jenis kesalahan yang dilakukan siswa pada kelas VIII MTs Pattuku dalam menyelesaikan soal matematika berdasarkan kriteria Watson pada pokok bahasan sistem persamaan linear dua variabel adalah data tidak tepat, prosedur tidak tepat, konflik level respon, masalah hierarki keterampilan dan selain ke-7 kategori diatas.

Siswa dalam kesalahan data tidak tepat, karena siswa kurang teliti dalam menuliskan data pada penyelesaian soal. Dalam kesalahan prosedur tidak tepat, siswa tidak melakukan langkah yang tepat dan siswa tidak mengerti cara yang digunakan untuk menyelesaikan soal.. Dalam kesalahan kesimpulan hilang, siswa tidak menuliskan kesimpulan akhir atau jawaban yang diminta dari soal karena siswa lupa menuliskan kesimpulan dan kurang mengetahui maksud dari pertanyaan. Dalam kesalahan konflik level respon, jawaban yang ditulis siswa salah, penyebabnya adalah siswa kurang teliti dalam menuliskan jawaban. Faktor penyebab kesalahan tersebut karena siswa bingung menggunakan alasan yang tepat untuk menyelesaikan soal. Dalam kesalahan hirarki keterampilan, ide aljabar siswa tidak tampak, penyebabnya siswa kurang teliti dalam melakukan perhitungan. Pada kesalahan selain ketujuh kategori di atas, siswa tidak menuliskan data yang diminta pada kolom diketahui dan ditanya. Siswa juga tidak menjawab pertanyaan pada metode substitusi. Faktor penyebab siswa melakukan kesalahan tersebut adalah kemampuan literasi dan manipulasi aljabar yang masih rendah.

Hasil penelitian ini dapat disarankan bagi siswa yaitu lebih sering memnyelesaikan soal-soal dalam bentuk cerita, dan menerjemahkan soal tersebut dalam model matematika serta berlatih menyelesaikan berbagai macam variasi soal supaya terbiasa dan meminimalisir kesalahan dalam menyelesaikan soal, sedangkan bagi guru yaitu dalam proses pembelajaran lebih menekankan dalam hal penguasaan konsep materi dengan memberikan banyak latihan atau bimbingan materi untuk meminimalisir siswa melakukan kesalahan dalam menyelesaikan soal.

\section{References}

Arikunto, S. 1993. Dasar-dasar Evaluasi Pendidikan. Jakarta: Rineka Cipta.

Isrokatun, I., Hanifah, N., Maulana, M., \& Suhaebar, I. (2020). Pembelajaran Matematika dan Sains secara Integratif melalui Situation-Based Learning. UPI Sumedang Press.

Kamariah, K. (2018). Analisis Kesalahan Siswa dalam Menyelesaikan Soal Himpunan Berdasarkan Kriteria Watson di Kelas VII MTs Syekh Yusuf Sungguminasa Kabupaten Gowa (Undergraduate thesis, Universitas Islam Negeri Alauddin Makassar). 
Santrock, J. W. 2012. Psikologi Pendidikan (3rd ed.). Jakarta: Salemba Humanika.

Saputri, R. R., Sugiarti, T., Murtikusuma, R. P., Trapsilasiwi, D., \& Yudianto, E. (2018). Analisis kesalahan siswa dalam menyelesaikan soal materi fungsi berdasarkan kriteria watson ditinjau dari perbedaan gender siswa SMP kelas VIII. Kadikma, 9(2), 59-68.

Yudianto, E. 2016. Profil Antisipasi Mahasiswa dalam Menyelesaikan Masalah Integral Berdasarkan Interpretasi , Prediksi dan Ramalan. (Seminar Nasional Matematika dan Pendidikan Matematika, UNY 2016). 327-334.

Wijaya, A. A., \& Masriyah. 2011. Analisis Kesalahan Siswa dalam Menyelesaikan Soal Cerita. Tesis yang tidak dipublikasikan. Surabaya: Unesa. 